

\title{
RELAÇÕES DE PODER NO INTERIOR DO CAMPO UNIVERSITÁRIO EAS LICENCIATURAS
}

\author{
JÚLIO EMÍLIO DINIZ PEREIRA \\ Faculdade de Educação da Universidade Federal de Minas Gerais
}

\section{RESUMO}

O objetivo deste artigo é buscar subsídios para uma melhor compreensão da situação atual de menor status acadêmico das licenciaturas nas universidades brasileiras e das conseqüentes dificuldades enfrentadas por esses cursos para implementação de mudanças significativas. São analisados resultados de uma investigação sócio-histórica realizada no curso de Ciências Biológicas da Universidade Federal de Minas Gerais - UFMG. A história desse campo, utilizada neste trabalho como um estudo de caso, revela pontos que poderão contribuir para um melhor entendimento dessa condição de menor prestígio acadêmico dos cursos de formação docente nas instituições de ensino superior brasileiras. FORMAÇÃO DE PROFESSORES - ENSINO SUPERIOR - LICENCIATURA

\begin{abstract}
POWER RELATIONS IN THE UNIVERSITY FIELD AND TEACHERS' EDUCATION COURSES. The goal of this article is to look for subsidies for a better understanding of the current situation of little academic status of teachers' education courses in the Brazilian Universities. It also aims to undestand the difficulty to bring about significant changes in such courses. Results of a socio-historic research in the Biological Sciences Course at the "Universidade Federal de Minas Gerais" - UFMG - are analysed in this work. The history of this field, used here as a case study, reveals significant points that can contribute to a better understanding of such little academic prestige of teachers' education courses in the Brazilian Universities.
\end{abstract}

Este artigo retoma e amplia questões tratadas em trabalho apresentado na 22-ㅡ Reunião Anual da ANPEd, em Caxambu (MG), de 26a 30 de setembro de 1999. 
O objetivo deste artigo é buscar subsídios para uma melhor compreensão da situação atual de menor statusacadêmico das licenciaturas nas universidades brasileiras e das conseqüentes dificuldades enfrentadas por esses cursos para implementação de mudanças significativas. Para tal, por meio da análise dos conflitos de natureza simbólica decorrentes de interesses em oposição no campo acadêmico, serão apresentados os resultados de uma investigação sócio-histórica realizada no curso de Ciências Biológicas da Universidade Federal de Minas Gerais.

O campo acadêmico, ou campo universitário, como outros campos simbólicos, é um campo de luta onde se opõem interesses de ordem simbólica. Segundo Bourdieu (1990, p. I 16), "a universidade também é o lugar de uma luta para saber quem, no interior desse universo socialmente mandatário para dizer a verdade sobre o mundo social (e sobre o mundo físico), está realmente (ou particularmente) fundamentado para dizer a verdade".

conceito de campo refere-se aos diferentes espaços sociais que possuem objetos de disputas e interesses específicos e por isso mesmo são irredutíveis aos objetos de lutas e aos interesses próprios de outros campos. Todavia, há leis gerais que regem os diferentes campos, ou seja, existem homologias estruturais e funcionais entre todos os campos. Sendo assim, "campos tão diferentes como o campo da política, o campo da filosofia, o campo da religião possuem leis de funcionamento invariantes" (Bourdieu, 1983a, p. 89).

A estrutura de um campo "é um estado da relação de força entre os agentes ou as instituições engajadas na luta ou, se preferirmos, da distribuição do capital específico' que, acumulado no curso das lutas anteriores, orienta as estratégias ulteriores" (Bourdieu, 1983a, p. 90). De uma maneira geral, todos os campos se estruturam a partir de relações de aliança e/ou conflito entre os seus diferentes agentes que lutam pela posse de determinadas formas específicas de capital. As hierarquias no interior de cada um desses campos se estabelecem pela maior ou menor detenção, por parte dos agentes, dessas formas específicas de capital.

Nos campos de produção de bens simbólicos e culturais a forma específica do capital que move as lutas no interior do campo é o capital simbólico expresso em formas de reconhecimento, legitimidade e consagração, institucionalizadas ou não, que os diferentes agentes ou instituições conseguiram acumular no decorrer das lutas no interior do campo (Bourdieu, 1990).

I. É o próprio Bourdieu que esclarece esse termo: "falar de capital específico é dizer que o capital vale em relação a um certo campo, portanto dentro dos limites desse campo, e que ele só é convertível em outra espécie de capital sob certas condições" ( $1983 a$, p. 90). 
O funcionamento de um campo depende da existência de "objetos de disputas e de pessoas prontas para disputar o jogo, dotadas de habitus ${ }^{2}$ que impliquem o conhecimento e reconhecimento das leis imanentes do jogo, dos objetos de disputa, etc." (Bourdieu, 1983a, p. 89).

universo da ciência está submetido às mesmas leis gerais da teoria dos campos e, ao mesmo tempo, assume formas específicas no interior desse campo. O campo científico

...é o lugar, o espaço de jogo de uma luta concorrencial. O que está em jogo especificamente nessa luta é o monopólio da autoridade científica definida, de maneira inseparável, como capacidade técnica e poder social; ou, se quisermos, o monopólio da competência científica, compreendida enquanto capacidade de falar e agir legitimamente (isto é, de maneira autorizada e com autoridade), que é socialmente outorgada a um agente determinado. (Bourdieu, 1983, p. 122-23)

De acordo com o mesmo autor, "o universo 'puro' da mais 'pura' ciência é um campo social como outro qualquer, com suas relações de força e monopólios, suas lutas e estratégias, seus interesses e lucros, mas onde todas essas invariantes revestem formas específicas" (Bourdieu, 1983, p. 122).

A história do campo das Ciências Biológicas na UFMG, utilizada neste trabatho como um estudo de $\mathrm{caso}^{3}$, revela pontos significativos que poderão contribuir

2. Por habitus (Bourdieu, 1983, 1989) se quer designar um sistema de disposições duráveis e socialmente constituídas que, incorporadas a um agente ou a um conjunto de agentes, orientam e dão significado às suas ações e representações. São "estruturas estruturantes" que ultrapassam o nível da consciência e fazem a mediação entre, de um lado, as estruturas sociais e, de outro, as práticas individuais. Constitui, ao mesmo tempo, um "ofício", um capital de técnicas, de crenças e referências em relação aos diferentes campos da vida social que orientam a ação dos indivíduos diante do mundo e são o fruto de sua história cultural e social pregressa.

3. Segundo Triviños, o "estudo de caso" é um dos mais relevantes tipos de pesquisa qualitativa em Ciências Sociais, constituindo-se em uma expressão importante dessa tendência na investigação educacional. Segundo esse autor, "o estudo de caso é uma categoria de pesquisa cujo objeto é uma unidade que se analisa aprofundadamente" (1992, p. 133). Na mesma direção, André, fundamentada em Aldeman et al., afirma que "o estudo de caso é um termo amplo, incluindo uma família de métodos de pesquisa cuja decisão comum é o enfoque numa instância" ( 1984 , p. 5I). Partindo dessa definição, autores como Nisbett e Watt sugerem que "o estudo de caso seja entendido como uma investigação sistemática de uma instância específica". Essa instância, segundo eles, "pode ser um evento, uma pessoa, um grupo, uma escola, uma instituição, um programa, etc." (idem, ibidem). De acordo ainda com Lüdke e André, o "caso" é sempre bem delimitado, devendo ter seus contornos claramente definidos no desenrolar do estudo. $\bigcirc$ "caso" pode ser similar a outros, mas é ao mesmo tempo distinto, pois tem um interesse próprio, singular. Fundamentadas em Goode e Hatt, elas afirmam que o casose destaca por constituir uma unidade dentro de um sistema mais amplo. "O interesse, portanto, incide 
para um melhor entendimento da atual situação de menor statusacadêmico dos cursos de formação docente nas universidades brasileiras. Essa história inicia-se no final da década de 30 com a criação da Faculdade de Filosofia que abrigou, entre outros, o curso de História Natural, responsável pela formação de professores de Biologia e de pesquisadores na área biológica.

\section{A EMERGÊNCIA DO CAMPO DAS CIÊNCIAS BIOLÓGICAS NA UFMG}

Inspirado no modelo original da Universidade de São Paulo - USP -, o grupo de fundadores da Faculdade de Filosofia de Minas Gerais - FFMG - tinha como ideal estabelecer em Belo Horizonte um espaço onde não houvesse uma preocupação restrita com o preparo para uma determinada profissão. Um lugar em que fosse possível pensar em temas de natureza mais geral, menos comprometido com uma aplicação imediata, com uma finalidade prática.

Esse espírito descomprometido dos fundadores da Faculdade de Filosofia pode ser verificado em um artigo publicado no primeiro número da Revista Kriterion, o periódico da faculdade lançado em 1947, em que a concepção fundamental da instituição e seus objetivos não se limitavam à formação de professores para o ensino secundário e normal:

Não sendo uma Faculdade puramente profissional como as demais, e tendo em vista principalmente realizar pesquisas desinteressadas nos vários domínios das ciências, das letras, da filosofia e da arte, isto é, nos vários domínios da alta cultura, da cultura desinteressada e integral, sem objetivos práticos, imediatistas, precisamente por isso a Faculdade de Filosofia prepara melhor do que nenhuma outra, o chamado trabalhador intelectual, técnico ou não. $\bigcirc$ que a Faculdade de Filosofia visa formar antes de tudo é o pesquisador, o cientista, o estudioso, o letrado, isto é, o homem que faz avançar a ciência e não somente o homem que repete a ciência feita pelos outros. Assim, no que toca ao professorado, por exemplo, a Faculdade de Filosofia quer formar professores que ensinem o que sabem e não o que acabam de ler.

De maneira semelhante ao ocorrido no restante do país, houve, na prática, desde a criação da Faculdade de Filosofia de Minas Gerais, o predomínio de interesses utilitários sobre os ideais culturais que guiavam muitos daqueles que lutaram

naquilo que ele tem de único, de particular, mesmo que posteriormente venham a ficar evidentes certas semelhanças com outros casos ou situações" (1986, p. 17). O curso de Ciências Biológicas da UFMG constitui-se no caso ou unidade que pretendemos estudar para melhor entender a situação atual dos cursos de formação docente nas universidades brasileiras. 
pela implantação de uma universidade que não se limitasse à formação de profissionais liberais. A faculdade cedeu a esses interesses utilitários quando percebeu que, logo após sua criação, a baixíssima demanda de seus cursos poderia comprometer o seu funcionamento. $\bigcirc$ texto do edital de convocação para exames vestibulares da época, endereçado aos estudantes dos colégios secundários da capital, esclarecia a utilidade de seus cursos:

Os diplomas que se obtêm na Faculdade de Filosofia serão exigidos, a partir de I은 de janeiro de 1943, para o preenchimento de qualquer cargo ou função do magistério secundário e normal e para o desempenho de outros cargos ou funções públicas que serão fixadas em leis especiais. (apud Haddad, 1988, p. 124-5)

Dessa forma, a Faculdade de Filosofia de Minas Gerais estava destinada, fundamentalmente, à formação do professor secundário. A pesquisa, apesar de ser uma atividade muito desejada, era bastante incipiente.

Essa faculdade possuía uma estrutura complexa com feições de uma microuniversidade, onde cinco seções (Filosofia, Ciências, Letras, Pedagogia e Didática) coexistiam no mesmo espaço, colocando em contato estudantes com interesses diversos, possibilitando uma convivência diversificada e rica intelectualmente. Era responsável pela realização de I I cursos ordinários, ministrados nas seções de Letras, Filosofia, Ciências e Pedagogia, com três anos de duração, que conferiam aos alunos o diploma de bacharel e um especial (curso de Didática). A seção de Didática, responsável por um curso de mesmo nome, realizado em apenas um ano, conferia o grau de licenciado ao formando na área específica do curso de bacharelado. Como se sabe, essa estrutura ficou conhecida com o nome de "esquema três mais um".

Os depoimentos coletados nessa investigação confirmam a falta de prestígio acadêmico da licenciatura, o que parece ser algo tão antigo quanto a própria origem do curso. Segundo a fala de uma das entrevistadas, os estudantes da Faculdade de Filosofia consideravam-se formados no final do terceiro ano, quando recebiam o diploma de bacharel. A licenciatura, apesar de ser o curso que dava uma perspectiva profissional para esses alunos, não passava de um apêndice do curso de bacharelado.

A gente recebia no fim do terceiro ano o diploma de bacharel, quer dizer todo mundo se formava bacharel no terceiro ano e depois fazia mais um ano para se formar licenciado. Então tínhamos dois diplomas, como eu tenho, diploma de bacharel e diploma de licenciado. A gente considerava que a formatura era no terceiro ano, depois a gente fazia mais um ano de Licenciatura, que era uma espécie de 
apêndice do curso. Mas, apesar disso, jamais passou pela cabeça de ninguém, eu acho, em nenhum dos cursos, que você tinha alguma coisa para fazer com esse bacharelado, que esse bacharelado lhe levasse para alguma coisa. Era uma coisa um pouco assim burocrática, convencional, tradicional, que no terceiro ano você se formava como bacharel, mas era tranqüilo que você só se formava mesmo profissionalmente com mais um ano. Mas a formatura era feita no terceiro ano. (risos). (Magda Becker Soares, entrevista em 18 de maio de 1995)

A Faculdade de Filosofia funcionava sob o regime da cátedra. Segundo Haddad ( 1988), a maioria dos professores era composta de profissionais liberais formados pelos cursos tradicionais da época, predominando bacharéis em Direito, engenheiros, médicos e farmacêuticos. $\bigcirc$ restante do quadro era composto por professores estrangeiros, padres e pessoas que não tinham curso superior mas atuavam com destaque na vida cultural de Belo Horizonte, como escritores, jornalistas e professores secundários. É importante ressaltar que as quatro únicas mulheres catedráticas da faculdade, diplomadas em Escola Normal e com cursos de especialização, regiam cadeiras nas seções de Pedagogia e Didática.

É necessário frisar também que a Faculdade de Filosofia possibilitou o acesso de um número maior de mulheres ao ensino de $3 \circ$ grau. Mais da metade dos formados nessa Faculdade, entre 1943/1955, era do sexo feminino.

Um grande número de mulheres encontrou assim uma possibilidade de estudar em curso superior. Os pais, às vezes, não deixavam as filhas entrarem nas escolas superiores de formação profissional tradicional, porque era um local para homens. Papai sempre foi muito aberto em relação à educação, de modo que ele me liberou... Eu, por exemplo, quando fui para a Escola, era a única mulher do curso de Engenharia. (Beatriz Gonçalves de Alvarenga, entrevista em 2 de junho de 1995)

Nessa época, o ensino e a formação para o magistério em nível superior "era, para a condição feminina, a alternativa possível, ou melhor, a mais rentável, para uma carreira de nível superior e a satisfação de ambições intelectuais" (Garcia, 1994, p. 78, destaque da autora).

Por estar ligada à formação de professores, atividade pouco valorizada socialmente, por abrir espaços para o ingresso de mulheres no seu corpo discente e docente e pelo fato de a pesquisa não ser uma atividade ainda bastante difundida, a faculdade de filosofia gozava de pouco prestígio em relação às escolas tradicionais.

Todas as escolas que não correspondiam à tradição universitária brasileira, ou seja, que saíam fora do padrão tradicional, das três grandes profissões, Engenha- 
ria, Medicina e Direito, eram consideradas como profissões de segunda categoria. Conseqüentemente as escolas que ministravam os respectivos ensinos não eram consideradas na distribuição do orçamento da universidade; normalmente a maior parte da União ficava com essas três grandes faculdades, as outras ficavam com o que sobrasse. (Márcio Quintão Moreno, entrevista em 2 de junho de 1995)

Além disso, a pesquisa realizada por Garcia ( 1994) constata que a Didática ${ }^{4}$, na Faculdade de Filosofia, ocupava um lugar desprestigiado e desvalorizado diante das outras seções que se responsabilizavam pelas disciplinas de conteúdo científico, "mais preocupadas em desenvolver as atitudes de pesquisa e experimentação nos seus respectivos campos do saber".

Segundo a autora, alguns fatores "contribuíram para a posição inferior que ocupou esse campo na hierarquia de saberes que constituíam as Faculdades de Filosofia": a natureza do conteúdo de Didática, que tinha "no seu horizonte imediato a profissionalização do magistério secundário", o fato de a maior parte do corpo docente das disciplinas pedagógicas ser formado por mulheres e, finalmente, o menor capital social e escolar dos/as primeiros/as catedráticos/as e professores/as que ocuparam as cadeiras da seção de Didática ${ }^{5}$ (Garcia, 1994, p. 1 17-9). Nas suas palavras,

Esse conjunto de atributos conferiram a esses professores um capital simbólico menor face aos professores das outras seções da Faculdade de Filosofia, quase na sua totalidade, portadores de diplomas de nível superior, obtidos nas tradicionais escolas de preparo para o exercício das profissões liberais. (Idem, p. 119)

A autora acrescenta que

...as disciplinas pedagógicas pelo fato de serem diretamente responsáveis pela aproximação com o campo profissional representavam um capitus diminutio para os "filósofos" que tinham no seu horizonte o pesquisador e não o papel de professor secundário. (Idem, ibidem)

4. A autora refere-se, ao mesmo tempo, ao "curso de Didática", que abrangia o conjunto das disciplinas pedagógicas responsáveis pela formação do futuro licenciado, e à "disciplina Didática" oferecida pela seção de mesmo nome da Faculdade de Filosofia.

5. Esses/as professores/as tinham sua origem social em frações das classes médias e eram oriundos/as do ensino primário com uma formação escolar e acadêmica que culminava na Escola Normal, quando muito, acrescida de algum curso de especialização, realizado em instituições que não tinham o status de escola de nível superior. 
Na Faculdade de Filosofia de Minas Gerais, a falta de uma formação adequada do corpo docente para a investigação científica, a precariedade das instalações físicas, a falta de recursos e o fato de os professores trabalharem em regime de tempo parcial, praticamente, inviabilizavam a realização da atividade cient́fica. Além disso, o mercado de trabalho oferecia maiores oportunidades para o magistério do que para a pesquisa.

Segundo Haddad (1988, p. I39), nessa faculdade, a área que mais cedo teve condições de se equipar para a concretização dos objetivos ligados à formaç̧ão de pesquisadores foi a de História Natural. O pioneirismo da História Natural no desenvolvimento da atividade científica fez com que esse curso se diferenciasse dos demais cursos da faculdade, apresentando particularidades na formação de professores e pesquisadores da área biológica.

O curso de História Natural, instalado na Faculdade de Filosofia de Minas Gerais em 1942, tinha originalmente o mesmo ideal do curso da USP, porém não possuía os mesmos recursos humanos e financeiros. Segundo os depoimentos, não estava claro para alunos e professores de História Natural qual era a finalidade desse curso na faculdade e que profissional se pretendia formar.

Alguns afirmaram que apesar da existência de dois diplomas, o de bacharel e o de licenciado, o curso estava fundamentalmente voltado para a formação de professores para o ensino secundário. Essa necessidade parecia evidente, uma vez que tal atividade era exercida por outros profissionais, principalmente da área médica, sem uma formação específica para o magistério.

Sendo assim, não havendo uma perspectiva profissional, nem uma definição clara a respeito do papel do bacharel em História Natural, esse curso tinha como produto final o professor, uma vez que a maioria dos alunos dirigia-se, ao final do terceiro ano, para a licenciatura. A intenção de formar o pesquisador existia na cabeça de alguns professores e era a pretensão da maioria dos alunos do curso de História Natural, porém não lhes eram dadas condições para tal formação. Além disso, as oportunidades de trabalho em pesquisa eram bastante restritas.

A presença e a atuação política do professor Braz Pellegrino na Faculdade de Filosofia, diretor no período de 1946 a 1948, foram essenciais para a criação e o reconhecimento oficial do curso de História Natural, bem como para o desenvolvimento da investigação científica nesse campo.

Em maio de 1946, o professor José Pellegrino, filho do professor Braz Pellegrino, foi indicado como assistente da cadeira de Biologia Geral do curso de História Natural e, no ano seguinte, em dezembro de 1947, o professor Giorgio Schreiber foi contratado, em regime integral, como interino de Zoologia (2 ${ }^{a}$ cadeira). Ambos apresentavam um currículo bastante diferenciado dos currículos dos 
demais docentes da Faculdade de Filosofia, podendo ser considerados autênticos pesquisadores ${ }^{6}$.

O professor Giorgio Schreiber, pesquisador italiano, era o único com o título de doutor em todo o curso e também o único com formação em História Natural. Veio para o Brasil em 1940, fugindo das perseguições fascistas na Europa. Ao ser convidado pelo professor Braz Pellegrino para compor o corpo docente do curso de História Natural da Faculdade de Filosofia de Minas Gerais, Schreiber exigiu algumas condições: contrato em tempo integral, sala para realizar seus trabalhos, assistente em tempo integral, aquisição de uma lista de livros, assinatura de revistas e uma cátedra.

O professor Schreiber, por ter sido formado na prática de pesquisa, foi o primeiro orientador de novos pesquisadores no curso de História Natural. "Seu método de trabalho influenciou a prática pedagógica do departamento, reforçando-a e adequando-a, para a construção do habitus de pesquisa" (Paixão, 1994, p. 17). Schreiber incentivava os alunos a acompanhar, pelos periódicos especializados, a produção científica no Brasil e no mundo, a participar de reuniões científicas e a empenhar-se em atividades de pesquisa.

Os alunos que estavam perto dele vivenciavam essa atmosfera da busca do conhecimento, não só da transmissão do conhecimento que era a tônica da Faculdade de Filosofia. O Schreiber mostrava o lado do conhecimento, do surgimento, o crescer do conhecimento e da aquisição do conhecimento. Então trabalhar com ele dava esse sentimento. Serviu muito de exemplo para todos nós, pois era uma pessoa que sabia descobrir as coisas. Ele fazia uma ação baseada numa reflexão, fazia uma reflexão baseada na ação, então, isso aí para os estudantes foi uma oportunidade ímpar. (Humberto Coelho de Carvalho, entrevista em 23 de janeiro de 1995)

Segundo Paixão (1994), a associação dos professores Braz Pellegrino e Giorgio Schreiber foi fundamental para o desenvolvimento da pesquisa biológica na FFMG. Apesar de estarem, politicamente, em campos opostos ${ }^{7}$, academicamente estavam comprometidos com a construção de uma "universidade moderna".

O professor José Pellegrino, formado em Medicina, tornou-se pesquisador reconhecido por seus trabalhos em biologia parasitária. Sua contratação contribuiu para incrementar a formação científica dos alunos do curso de História Natural.

6. Segundo o Guia da Faculdade de Filosofia da Universidade de Minas Gerais, até o ano de 1953, já haviam publicado mais de 50 trabalhos, sendo a maioria em revistas estrangeiras.

7. A pesquisadora chama atenção para o curioso fato de o professor Braz Pellegrino, italiano e amigo da fascista Casa de Itália, ter convidado para trabalhar na Faculdade de Filosofia o compatriota judeu Giorgio Schreiber, que viera para o Brasil fugindo do regime anti-semita europeu. 
Apesar de não ter sido um grande "mestre", como o professor Schreiber, José Pellegrino teve importância na formação de uma nova geração de pesquisadores.

Pode-se dizer, então, que o surgimento da pesquisa no curso de História Natural está associado à entrada desses dois novos professores em seu quadro docente. As contratações desses pesquisadores possibilitaram o desenvolvimento de linhas de investigação no curso. De acordo com Haddad,

.... grande número de pesquisas realizadas, intensa participação em Congressos científicos e inúmeras publicações de grande projeção na área são indicadores de sua atividade de pesquisador dedicado também ao ensino. Como conseqüência da presença de professores bem preparados para atividades científicas, tendo inclusive o privilégio de contar com um professor em regime integral, o curso de História Natural conseguiu, mais cedo, resultados positivos na vinculação ensino e pesquisa. $(\mid 988$, p. $|40-4|)$

Ainda em 1947, o esforço conjunto do catedrático de Biologia Geral Braz Pellegrino, de seu assistente José Pellegrino e do professor interino da 2 a cadeira de Zoologia Giorgio Schreiber já lançaria as bases para a criação do "Instituto de Biologia e de Pesquisas Correlatas" da Faculdade de Filosofia, um importante passo em direção à consolidação da prática de pesquisa no curso de História Natural.

Segundo palavras do próprio professor Braz Pellegrino,

...procurou o Instituto de Biologia ser, acima de tudo, uma manifestação viva e genuína daquele espírito universitário sempre invocado mas cada vez mais afugentado do meio assim chamado universitário (...) Um instituto é, antes de tudo, uma unidade de pesquisa assim como uma cadeira é essencialmente uma unidade didática. Esta divisão poderia, em tese, parecer imprópria, pois não se exclui, antes se exige que em qualquer cadeira possa e deva haver pesquisa. (Ofício enviado ao Magnífico Reitor da Universidade de Minas Gerais, professor Lincoln Prates, em 23/I I/1957)

Uma manobra do catedrático de Biologia Geral fez incluir no primeiro Regimento Interno da FFMG a previsão da criação de um laboratório de biologia orientado e dirigido pelo próprio professor. "Essa previsão regimental, atribuindo possibilidades para a criação de laboratórios ligados às cadeiras de ciências, possibilitou com mais agilidade, a criação do Instituto de Biologia" (Haddad, 1988, p. 140).

Apesar de receber referência especial no Anuário da Faculdade de Filosofia (1939-1953) e no Guia da Faculdade (1953), não havia um estatuto ou regimento interno específico que legalizasse a existência do Instituto de Biologia. Segundo justificativa do professor Braz, "o bom senso e a grande vontade de realizar, de 
servir à causa da Universidade organizaram sua forma de vida interna e ditaram suas normas de conduta" (Ofício enviado ao Magnífico Reitor da Universidade de Minas Gerais, professor Lincoln Prates, em 23/I I/1957).

A criação do Instituto de Biologia foi na verdade uma estratégia ${ }^{8}$ que tornou possível a concentração de recursos materiais e humanos das duas cátedras diferentes, Biologia Geral e Zoologia (2 ${ }^{a}$ cadeira), em torno de um objetivo comum, privilegiar um trabalho visando ao fomento à pesquisa.

Segundo o depoimento de um dos entrevistados,

Esses professores, eles dividiam as parcas verbas e assim compravam material, davam bolsas, jogavam com o dinheiro (...). Então eles conseguiam várias coisas que os outros não conseguiam. Para comprar um aparelho caro, somavam-se os dois e adquiriam o equipamento. Então assim eles conseguiram sobreviver. Em média as disciplinas da Biologia Geral e da Zoologia eram melhores... porque tinham mais condições, eram aulas mais modernas, em termos de biologia mais avançadas e isso por causa da pesquisa que estava lá... então eles captavam recursos mais fácil e eles distribuíam ali as bénéfices... (Humberto Coelho de Carvalho, entrevista em 23 de janeiro de 1995)

Os dizeres do próprio professor Braz Pellegrino confirmam o depoimento anterior.

Escassos nos princípios, praticamente nulos em seguida, foram melhorando com a simbiose realizada entre as cadeiras de Biologia Geral e Zoologia II. Vis unita fortior! As verbas das duas cadeiras possibilitaram a aquisição de material indispensável para o trabalho. (Ofício enviado ao Magnífico Reitor da Universidade de Minas Gerais, professor Lincoln Prates, em 23/I I/1957)

Os resultados dessa simbiose foram sentidos logo nos primeiros anos de funcionamento do Instituto de Biologia. Os relatórios correspondentes aos exercícios financeiros e à prestação de contas da Faculdade de Filosofia são a prova do sucesso desse empreendimento. Por exemplo, no biênio 1948-1949, a rubrica "despesas referentes à seção de ciências naturais" mostra que os gastos de materiais de laboratório foram todos para o Instituto de Biologia, não havendo referências às outras matérias do curso nem às cadeiras de Física e Química. No ano

8. As estratégias, com o sentido que the é atribuído por Bourdieu (1983a, 1990), são "ações inteligíveis, mas não necessariamente inteligentes ou resultantes de um cálculo racional e cínico, que orientam as escolhas e os interesses dos agentes em função de um habitus adquirido e das possibilidades que um determinado campo oferece para obtenção e maximização dos lucros específicos em jogo no campo em questão". 
seguinte, ou seja, em 1950, praticamente a metade da verba patrimonial da faculdade foi destinada ao instituto.

Usando de seu crescente prestígio no campo acadêmico da Faculdade de Filosofia, o Instituto de Biologia obteve, por meio da "compreensão da Administração da Faculdade e da solidariedade da Congregação", uma verba anual própria para atender a algumas despesas extraordinárias. Além disso, passou a receber recorrentemente auxílio financeiro da Fundação Rockefeller, o que representava um grande estímulo às pretensões desse grupo.

Apesar dos privilégios conquistados dentro da Faculdade de Filosofia, o Instituto de Biologia sonhava com sua autonomia para o desenvolvimento da pesquisa pura na área biológica. Em ofício enviado ao reitor da Universidade de Minas Gerais, o professor Braz Pellegrino escreve:

A única solução que se nos afigura justa e viável é a de colocar-se o instituto em situação eqüidistante de faculdades às quais poderia servir, e ligado diretamente à reitoria como unidade neutra a serviço do ensino e da pesquisa. (Ofício enviado ao Magníico Reitor da Universidade de Minas Gerais, professor Lincoln Prates, em 23/II/1957)

As diferentes concepções a respeito dos objetivos daquela instituição acabaram por dividir os grupos, determinando assim a própria divisão do espaço na Faculdade de Filosofia. $\bigcirc$ Instituto de Biologia já prenunciava a especificidade de um grupo que se direcionava para a atividade de pesquisa e se preparava para tornar hegemônico, a partir da Reforma Universitária de 1968.

\section{A REFORMA UNIVERSITÁRIA E A CONSOLIDAÇÃO DAS CIÊNCIAS BIOLÓGICAS NA UFMG}

Como se sabe, é a partir da n. Lei 5.540/68, mais conhecida como Lei da Reforma Universitária, que os cursos de licenciatura sofrem uma grande transformação, uma vez que ela retira das Faculdades de Filosofia, Ciências e Letras a responsabilidade total pela formação do licenciado. Além disso, todas as demais propostas da Reforma Universitária deixam sua marca na nova configuração da licenciatura.

Essa lei, ao estabelecer o princípio da indissociabilidade ensino/pesquisa, propõe a pesquisa como elemento associado, em igualdade de condições, à atividade de ensino. Observa-se, a partir desse momento, o reconhecimento e fortalecimento institucional da prática de pesquisa nas universidades.

Segundo Paixão (1994, p. I), "a reorganização da Universidade proposta pela 
reforma foi objeto de disputa, opondo interesses acadêmicos hegemônicos e interesses acadêmicos emergentes, que procuravam impor-se". O modelo organizacional da universidade moderna proposto pela Reforma respondeu aos interesses de ordem acadêmica do grupo espećífico ligado à pesquisa. A ele se opunha o grupo, que se identificava com a formação profissional e, conseqüentemente, com o ensino da graduação.

Observam-se, a partir daí, uma reorganização das relações de poder no campo universitário brasileiro e uma nova orientação na distribuição de capital específico desse campo. A pesquisa passa a ser a principal atividade acadêmica e os méritos dela advindos são acumulados na forma de capital científico. Os principais indicadores de posse desse tipo de capital são as publicações, em especial as internacionais, as apresentações de trabalho em congressos científicos, as orientações de teses e dissertações e o reconhecimento de seus pares-concorrentes, outros membros da comunidade científica. Nesse contexto, o ensino (de graduação) é pouco valorizado e pouco ou nada contribui para a acumulação de capital cient́fico.

A criação dos institutos centrais representou um passo importante no sentido da consolidação da prática de pesquisa na universidade. Por outro lado, o ensino de graduação e, mais especificamente, o ensino voltado para a formação profissional vão seguir um processo gradativo de perda de espaço institucional e importância simbólica.

Na UFMG, o movimento de reforma encontrou grande resistência por parte dos catedráticos mais ligados às unidades tradicionais. As maiores reações à reforma vinham principalmente de setores ligados à Faculdade de Medicina e à Escola de Engenharia, com apoio de setores de outras unidades que "dispunham de menor participação na estrutura de poder", como a Farmácia e a própria Filosofia. Essa reação porém não foi unânime, existindo grupos dentro dessas instituições interessados nos desdobramentos da reforma.

Houve, por exemplo, apoio de alguns catedráticos da área básica da Faculdade de Medicina como o Professor Amílcar Vianna Martins, pesquisador pioneiro na área de Parasitologia, que viu na criação do Instituto de Ciências Biológicas uma solução promissora para a valorização da pesquisa básica e o desenvolvimento de cursos de pós-graduação. (Haddad, 1988, p. 150)

O estudo realizado por Paixão (1994), ao relatar o conflito entre cátedras da área básica e cátedras da área profissional na Faculdade de Medicina, explicita as tensões e as dificuldades de implantação do Instituto de Ciências Biológicas na UFMG. De acordo com a autora,

A estrutura universitária, produzida pelo agregado de faculdades e articulado em 
torno da cátedra, privilegiava a formação profissional. Nessa estrutura, a pesquisa e seus agentes ocupavam lugar secundário. Assim, compreende-se que essa categoria docente almejasse uma reorganização da universidade que lhes fosse mais favorável. (Idem, p. 18)

Tratava-se, segundo a autora, de dar nova organização à universidade, transformando-a numa instituição produtora do saber, nos moldes das universidades modernas. Isso supunha o enfrentamento dos interesses das faculdades profissionais de prestígio que dominavam a universidade. Os agentes da prática emergente articularam-se propondo uma nova estrutura em que a prática de pesquisa fosse hegemônica.

Na Faculdade de Medicina, por exemplo, as tensões foram produzidas pela oposição de interesses simbólicos entre "catedráticos-médicos", aqueles que se ocupavam das cadeiras do ciclo profissional e identificavam-se, prioritariamente, com a formação profissional e "catedráticos-pesquisadores", responsáveis pelas cadeiras básicas e que priorizavam a prática da pesquisa9. Esse grupo ligado às áreas básicas aderiu à idéia da criação do Instituto de Ciências Biológicas - ICB -, pois ali as atividades de pesquisa e de formação de novos pesquisadores na área biológica, com a criação dos cursos de pós-graduação, seriam prioritárias e a Biologia, como disciplina autônoma, encontraria condições de se afirmar.

Enquanto na Medicina, Odontologia, Farmácia e Veterinária a pesquisa ocupava no currículo e no espaço institucional um lugar secundário, de apoio às cadeiras de formação profissional, na Faculdade de Filosofia sua situação era diferente. No curso de História Natural, os "catedráticos-pesquisadores" gozavam de prestígio na estrutura acadêmica do poder, pois ali a formação profissional não era dominante e a formação de professor não era socialmente prestigiada. Por outro lado, "se internamente o lugar da pesquisa era mais confortável, no confronto com as faculdades de prestígio, no âmbito da Universidade, a Faculdade de Filosofia era desprestigiada" (Paixão, 1994, p. 18).

9. De acordo com Bourdieu (1983, p. 136-40), nas lutas no interior do campo, os agentes ou grupos de agentes concorrentes desenvolvem estratégias de "conservação" e "exclusão", ou então, estratégias de "subversão" de acordo com suas posições relativas no interior do campo. Essas estratégias, as primeiras levadas a efeito pelas ortodoxias (aqueles que ocupam as posições dominantes no interior do campo), e as segundas, implementadas pelas heterodoxias (aqueles que ocupam as posições dominadas no campo ou que são dele excluídos), visam, em última análise, defender ou conquistar uma determinada posição dominante, nas hierarquias constitutivas do campo, que se expressa no poder de definir os critérios e o monopólio do exercício legítimo de uma determinada atividade científica. 
Sendo assim, até o final dos anos 60 a pesquisa biológica na UFMG ocupava posições dominadas. Na análise de Paixão, "dominada no interior da Faculdade de Medicina, faculdade de prestígio. Dominante na Faculdade de Filosofia, faculdade de pouco prestígio" (1994, p. I8). Essa situação, porém, começará a se inverter a partir da consolidação dos institutos centrais na universidade e, em especial, da criação do Instituto de Ciências Biológicas, onde a prática da pesquisa, prática heterodoxa, tornar-se-á hegemônica.

Após conquistarem essa luta concorrencial, resultado de um investimento herético de longo prazo, os novos agentes do campo passam a aumentar seus lucros e a disputar os novos dividendos. A constituição do ICB/UFMG, a formação de seus departamentos, a criação do curso de Ciências Biológicas e as suas transformações são exemplos claros das tensões e das novas relações de poder instituídas no interior desse campo universitário a partir da reforma.

A ocupação do espaço físico do Instituto de Ciências Biológicas da UFMG, um prédio verticalizado de quatro andares e 17 blocos com uma área construída de mais de 46 mil metros quadrados, e a distribuição de seus departamentos nesse espaço constituem exemplos de como as novas forças passam a se relacionar no interior desse campo.

Os departamentos que hoje compõem o ICB originaram-se basicamente de duas vertentes: os que vieram das escolas e faculdades de prestígio que abrigavam disciplinas de biologia aplicada (Faculdades de Medicina, Farmácia, Odontologia e Escola de Veterinária), vertente biomédica, e outra, da Faculdade de Filosofia, instituição de pouco prestígio, onde eram formados os professores e pesquisadores em biologia básica, a vertente biológica do ICB. Da primeira, originaram-se os departamentos de Morfologia, Bioquímica e Imunologia, Parasitologia, Microbiologia, Fisiologia e Biofísica, Farmacologia e Patologia Geral. Da última vertente, originaram-se os departamentos de Biologia Geral, Botânica e Zoologia.

A Morfologia e a Bioquímica, por exemplo, foram os primeiros departamentos a se mudarem para as novas instalações no campus da Pampulha, e a Faculdade de Medicina resistia à saída desses departamentos e, também, à chegada de um novo grupo de professores na faculdade. A transferência dessas disciplinas não era desejada, principalmente pelo setor profissional, por envolver os seus mais prestigiados pesquisadores, bem como os equipamentos e os recursos financeiros. A Bioquímica, que ocupa atualmente grande área do quarto andar do prédio do ICB/NFMG, foi o primeiro departamento do ICB a organizar seu curso de pós-graduação.

A cátedra de Biologia Geral do curso de História Natural da antiga Faculdade de Filosofia passou a constituir o novo departamento de Biologia Geral, respon- 
sável pelas disciplinas da área de Genética, Evolução e Ecologia. As disciplinas comuns a outros departamentos como Citologia, Histologia, Embriologia e Fisiologia foram transferidas para seus respectivos novos departamentos, ou seja, Morfologia, as três primeiras, e Fisiologia, a última.

Apesar da adesão ao projeto de reestruturação da universidade e do apoio à criação do Instituto de Ciências Biológicas, os professores do curso de História Natural, principalmente o grupo liderado pelo professor Giorgio Schreiber, receavam ser engolidos pelos colegas da vertente biomédica no novo espaço de trabaIho. E, pelo depoimento de um dos entrevistados, foi o que realmente aconteceu:

A partir dessa passagem da História Natural para o curso de Ciências Biológicas, o centro de decisão deixou de ser aquele grupo que influenciava na Botânica, na Zoologia, na Biologia. Passaram a exercer influência também outros grupos, os de formação médica e não era o núcleo antigo do curso de Ciências Biológicas. A grande mudança que houve é que, de repente, o núcleo antigo do curso de História Natural ficou afogado, ficou um grupinho pequeno em relação à enorme massa dos outros departamentos que compunham o instituto. (Luiz Alexandre Fallieri, entrevista em 30 de março de 1995)

Em 1970, ao apresentar uma nova proposta curricular para o Instituto de Ciências Biológicas, a Comissão de Implantação do Currículo do ICB/UFMG, que estudou e propôs a estrutura curricular a ser adotada no instituto, sugere sua aplicação imediata, pois

.... atraso na aplicação do novo currículo daria oportunidade à cristalização dentro do ICB de idéias filiadas ao antigo sistema, as quais seriam de extirpação muito mais difícil, se não se aproveitar a oportunidade criada pelo "clima" da reforma. (UFMG, 1970, p. 47)

Nesse relatório, surge a proposta de criação do curso de Ciências Biológicas em substituição ao curso de História Natural, este último associado ao chamado "antigo sistema". Segundo esse documento, "a criação deste curso, aliás, é uma antiga aspiração do corpo docente do atual curso de História Natural” (idem, p. 27). No entender dessa comissão, uma das principais falhas do curso da antiga Faculdade de Filosofia estaria no não-cumprimento da finalidade de formar professores e pesquisadores na área biológica e se justifica assim:

Ele [o curso de História Natural] ministra conhecimentos profundos demais para professores de ensino médio, embora pouco profundos para formação de pesquisadores e professores de ensino superior. (Idem, p. 26) 
O curso de História Natural foi considerado inadequado para a tarefa de formar pesquisadores e professores universitários também em razão de sua característica generalista, por tentar associar matérias da geociências e das ciências biológicas, algo que parecia cada vez mais difícil diante da rapidez com que os conhecimentos cientííicos vinham se acumulando e devido à diferenciação entre as técnicas aplicadas ao estudo das duas áreas.

Todavia, a decisão de substituir o curso de História Natural pelo de Ciências Biológicas não foi uma idéia original da comissão de Implantação do Currículo do ICB/UFMG. Na verdade, o relatório dessa Comissão procurou adaptar-se à Resolução $107 / 69$ do Conselho Federal de Educação - CFE -, que revogou as resoluções anteriores relativas ao currículo mínimo e à duração dos cursos de Ciências Biológicas e História Natural ${ }^{10}$, e fixou normas para a criação dos novos cursos de Licenciatura e de Bacharelado em Ciências Biológicas. Em relação ao Bacharelado, essas normas eram dirigidas apenas para a modalidade médica.

A Resolução 107/69, oriunda do Parecer 107/69, ao estabelecer o currículo mínimo para a Licenciatura e para o Bacharelado, modalidade médica, em Ciências Biológicas, distingue um tronco comume uma parte específica para cada uma dessas habilidades.

Deste modo, a proposta de um novo currículo para o curso de Ciências Biológicas do ICB/NFMG encontrou apoio na Resolução 107/69. Na estrutura apresentada pela comissão haveria um básico geral, com disciplinas comuns aos outros cursos, um básico específico o o terceiro e o quarto ano profissional, tendo o aluno de optar por uma área de concentração. Essa proposta ainda sofreu algumas alterações antes de se constituir no primeiro currículo do novo curso de Ciências Biológicas.

Finalmente, o curso de Ciências Biológicas da UFMG foi oficialmente criado em 1972. O primeiro currículo desse novo curso foi proposto por uma comissão especial de professores do ICB, dessa vez com maior representatividade dos professores da vertente biológica. O curso do ICB/UFMG foi, então, organizado tendo um tronco comum, completado em três períodos, e um ciclo específico ( $\mathrm{Li}$ cenciatura ou Bacharelado), cursado a partir do quarto período.

O Guia do Aluno, que trazia informações gerais sobre o curso recém-criado, apontava também os destinos dos formandos: "o licenciado em Ciências Bio-

10. Em 1964, o CFE estabeleceu um currículo mínimo para a Licenciatura em Ciências Biológicas (Resolução n. 30/64). Em 1966, o CFE fixou pela primeira vez o currículo mínimo para o Bacharelado em Ciências Biológicas, modalidade médica (Resolução n. 57I /66). 
lógicas terá sua área de atuação na parte de ensino de Biologia para o 2o grau. Os graduados em Bacharelado deverão dirigir-se aos cursos de pós-graduação, ao magistério superior e/ou dedicar-se à pesquisa".

A partir daí o bacharelado começa a ter realmente uma cara. Porque antes não existia, você não via, quer dizer: "o que era ser um bacharel?" Agora não, agora você já tem alguma coisa que realmente o distingue. (Sílvia Elizabeth Gerken, entrevista em 10 de maio de 1995)

O Bacharelado passa a identificar-se definitivamente com a atividade de pesquisa. Essa modalidade começa a ser considerada o primeiro passo na carreira acadêmica, na formação de novos pesquisadores. A partir daí, os alunos do bacharelado apresentam-se como uma boa opção de investimento pelos novos dominantes desse campo, de acordo com a expressão de Bourdieu.

Percebe-se então que a Reforma de 1968 e a consolidação dos institutos básicos na universidade instauram a supremacia dos novatos no campo acadêmico, daqueles agentes dotados de um habitus de pesquisa, que possuem e acumulam capital científico por meio da atividade de investigação. Conseqüentemente, passaram de dominados a dominantes, e a pesquisa transformou-se em uma prática ortodoxa, vindo a ter um alto preço no campo universitário brasileiro. Os novos dominados são aqueles que se ocupam principalmente do ensino (de graduação), atividade cada vez menos valorizada nesse campo.

\section{CONSIDERAÇÕES FINAIS}

O menor status acadêmico da atividade de ensino em relação à pesquisa, da graduação comparada à pós-graduação, da Licenciatura em relação ao Bacharelado, e as dificuldades de implementação de mudanças nos cursos de formação de professores são hoje o reflexo das relações de força, das lutas e estratégias, dos interesses e lucros estabelecidos no campo universitário brasileiro desde a sua origem. Os desafios colocados para a melhoria dos cursos de licenciatura talvez sejam muito maiores que uma simples reforma curricular, mudanças nas ementas, nos nomes e na carga horária das disciplinas ou na concepção de formação de professores que se tem hoje nas universidades.

Por outro lado, não são medidas simplistas e banalizadoras que procuram retirar das universidades a responsabilidade pela formação docente que irão resolver os problemas atuais das licenciaturas. Além disso, a não-valorização do profissional da educação, seus salários aviltantes, as precárias condições de trabalho e a 
falta de um plano de carreira para a profissão continuam sendo problemas fulcrais que prosseguem sem solução em nosso país e que afetam diretamente as questões da formação inicial de professores.

\section{REFERÊNCIAS BIBLIOGRÁFICAS}

ANDRÉ, M.E.D.A. Estudo de caso: seu potencial na educação. Cadernos de Pesquisa, n. 49, p. 5I-4, maio 1984.

BOURDIEU, P. O Campo científico. In: ORTIZ, R. (org.). Pierre Bourdieu. sociologia. São Paulo: Ática, 1983, p. 122-55.

. Coisas ditas. São Paulo: Brasiliense, 1990, p. 77-95: O Campo intelectual: um mundo à parte.

. O Poder simbólico. Lisboa: Difel, 1989, p. 59-73: A Gênese dos conceitos de habitus e de campo.

. Questôes de sociologia. Rio de Janeiro: Marco Zero, 1983a, p. 89-94: Algumas propriedades dos campos.

FACULDADE DE FILOSOFIA DE MINAS GERAIS. Anuário da Faculdade de Filosofia da Universidade de Minas Gerais (1939-1953). Belo Horizonte, 1953.

- Guia da Faculdade de Filosofia da Universidade de Minas Gerais. Belo Horizonte, 1953.

GARCIA, M. M. A. Tempos pioneiros: a constituição do campo da didática no ensino superior brasileiro. Belo Horizonte, 1994. Dissert. (mestr.) Faculdade de Educação da UFMG.

HADDAD, M. L. A. Faculdade de Filosofia de Minas Gerais, raízes da idéia de universidade na UMG. Belo Horizonte, 1988. Dissert. (mestr.) Faculdade de Educação da UFMG.

LÜDKE, M., ANDRÉ, M. Pesquisa em educação: abordagens qualitativas. São Paulo: EPU, 1986.

PAIXÃO, L. P. Cátedra e hegemonia da prática docente na Faculdade de Medicina da UFMG. In: REUNIÃO ANUAL DA ANPED, 17, Caxambu, 1994. Anais. Belo Horizonte: ANPEd, 1994.

TRIVIÑOS, A. N. S. Introdução à pesquisa em ciências sociais. a pesquisa qualitativa em educação. 3. ed. São Paulo: Atlas, 1992.

UFMG. Instituto de Ciências Biológicas. Currículo do Instituto de Ciências Biológicas: relatório da Comissão Especial destinada ao estudo, planejamento e implantação do currículo do ICB da UFMG. Belo Horizonte, 1970. 
